\title{
Delta-Like Ligand 4 Correlates with Endothelial Proliferation and Vessel Maturation in Human Malignant Glioma
}

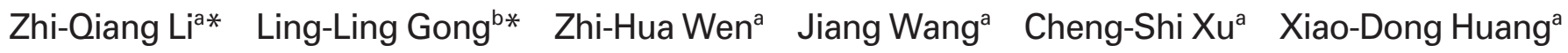 \\ ${ }^{a}$ Department of Neurosurgery, ${ }^{b}$ Department of Pathology, Zhongnan Hospital of Wuhan University, Wuhan, China
}

\section{Keywords}

Delta-like ligand 4 - Microvessel · Angiogenesis . Malignant glioma

\section{Summary}

Aim: To investigate the role of delta-like ligand 4 (DLL4) in the angiogenesis of high-grade malignant glioma. Materials and Methods: DLL4 expression and microvessel density (MVD) were detected by immunohistochemistry in 51 human high-grade malignant glioma tissue samples. The vessel maturation index (VMI) was calculated as the percentage of $\alpha$-smooth muscle actin ( $\alpha$-SMA)-positive vessels in relation to the amount of CD31-positive vessels. Double fluorescent immunostaining for CD31 and EphrinB2 or EphB4 was performed to identify the arterial (EphrinB2) or venous (EphB4) origins of glioma microvessels. Results: Strong immunostaining of DLL4 and a positive correlation of DLL4 with the MVD were observed in high-grade malignant gliomas. The VMI of the DLL4-positive group was significantly higher than that of the DLL4-negative group. However, no significant association was found between DLL4 and EphrinB2 or EphB4 in high-grade gliomas. Conclusion: DLL4 may be an important regulator for vessel proliferation and maturation in human high-grade malignant gliomas.

\section{Introduction}

Malignant glioma, the most common primary tumor in the central nervous system, exhibits many vessel-related pathological features [1], including marked endothelial proliferation, tortuous and disorganized vessels susceptible to high permeability, and larger diameters with thicker basement membranes than those of the normal brain. Aberrant microvasculature

*These two authors contributed equally to this work.

\section{KARGER}

Fax +497614520714

Information@Karger.de

www.karger.com

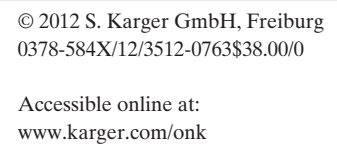

\section{Schlüsselwörter}

Delta-like Ligand 4 - Mikrogefäß . Angiogenese ·

Gliom, malignes

\section{Zusammenfassung}

Ziel: Die Erforschung der Rolle des Delta-like Liganden 4 (DLL4) in der Angiogenese von hochgradig malignen Gliomen. Material und Methoden: Die DLL4-Expression und Mikrogefäßdichte (MVD) wurden mittels Immunhistochemie in 51 Gewebeproben von hochgradig malignen Gliomen nachgewiesen. Der Gefäßreifungsindex (VMI) wurde als Prozentsatz der $\alpha$-Smooth Muscle Actin ( $\alpha$-SMA)-positiven Gefäße bezogen auf die Menge der CD31-positiven Gefäße berechnet. Eine zweifache Immunfluoreszenzfärbung spezifisch für CD31 und EphrinB2 oder EphB4 wurde durchgeführt, um die arterielle (EphrinB2) oder venöse (EphB4) Abstammung der Mikrogefäße in Gliomen zu bestimmen. Ergebnisse: In hochgradig malignen Gliomen wurden eine starke Immunfärbung spezifisch für DLL4 und eine positive Korrelation von DLL4 mit der MVD beobachtet. Der VMI der DLL4-positiven Gruppe war signifikant höher als der der DLL4-negativen Gruppe. Jedoch wurde keine signifikante Assoziation zwischen DLL4 und EphrinB2 oder EphB4 in hochgradigen Gliomen gefunden. Schlussfolgerung: DLL4 könnte ein wichtiger Regulator für die Gefäßproliferation und -reifung in hochgradig malignen Gliomen des Menschen sein.

usually appears as 'glomeruloid tufts' consisting of multilayered, mitotically active endothelial cells and perivascular cells [2]. Intriguingly, one of the most aggressive gliomas, glioblastoma multiforme (GBM), is a highly vascularized tumor, but the microcirculation within the tissues is very inefficient and may contribute to relative hypoxia and necrosis within a given tumor [3]. This indicates that the mere existence of vessels does not necessarily correlate with their functionality, and having numerous small vessels may not result in adequate perfusion [4]. 
With the increasing accumulation of knowledge regarding angiogenesis, not only the vascular morphology but also the vascular function has received much attention. To date, vascular endothelial growth factor (VEGF) and delta-like ligand 4 (DLL4), a new member of the Notch ligand family, are the only 2 genes known to develop vasculature with haploinsufficiency that leads to major vascular defects and embryonic lethality [5]. Interestingly, many processes involved in tumor angiogenesis resemble embryonic vascular development. In previous studies, VEGF has been identified to play an important role in the development of glioma angiogenesis [6]. Recently, several groups have reported that DLL4 expressed in tumor cells can activate Notch signaling in host stromal/ endothelial cells, increase the size of blood vessels and improve vascular function within tumors. On the other hand, DLL4 blockade can promote nonproductive angiogenesis, which results in an inhibition of tumor growth and a decrease in tissue perfusion, accompanied by an increase in vascular density [7-10]. These findings suggest that, similar to VEGF, DLL4 may also be involved in the maturation of tumor blood vessels, which is the prerequisite for maintaining vascular function.

Therefore, the aim of this study was to investigate the role of DLL4 in malignant glioma, by studying the differential expression of DLL4 in normal human brain tissues and highgrade malignant gliomas. In addition, we sought to analyze the association between DLL4 expression and vessel maturity to provide some insight into the pathological mechanisms.

\section{Materials and Methods}

\section{Patients and Tissue Samples}

Human tissue samples from 13 patients diagnosed with anaplastic astrocytoma (grade III; AIII), 14 patients diagnosed with anaplastic oligodendroglioma (grade III; OIII), and 24 patients diagnosed with glioblastoma multiforme (grade IV; GBM) were obtained postoperatively from the Department of Neurosurgery, Zhongnan Hospital, Wuhan University. A total of 7 normal brain tissues were resected from patients with severe craniocerebral trauma who underwent internal decompression. Surgeries were performed between 2004 and 2008. Written consent was obtained from all subjects and the medical ethics committee of Zhongnan Hospital, Wuhan University, approved the study. The subjects comprised 31 men and 20 women, and their ages ranged from 22 to 63 years, with a median age of 45.4 years. All tissues were fixed in buffered $4 \%$ paraformaldehyde (pH 7.4) and embedded in paraffin casts before the histological sections were prepared during the histopathological examinations. Tumors were sorted and graded independently by 2 experienced neuropathologists blind to the study design, using the World Health Organization brain tumor classification [11].

\section{Immunohistochemistry}

Paraffin-embedded sections were used for immunohistochemical analysis. Standard biotin-streptavidin (S-P) immunohistochemical staining was conducted in all paraffin-embedded tissue blocks, which were serially sectioned $4 \mu \mathrm{m}$ thick. The staining procedure was performed as previously described $[12,13]$ with some modifications. Briefly, paraffin-embedded tissue sections were dewaxed and rehydrated in serial alcohol washes, and then the endogenous peroxidase activities were blocked. After the nonspecific sites were saturated with $5 \%$ normal goat serum, the sections were incubated serially with the primary antibodies, biotinylated secondary antibodies, and the biotin-peroxidase complex. Finally, the sections were counterstained with hematoxylin. In parallel,
A

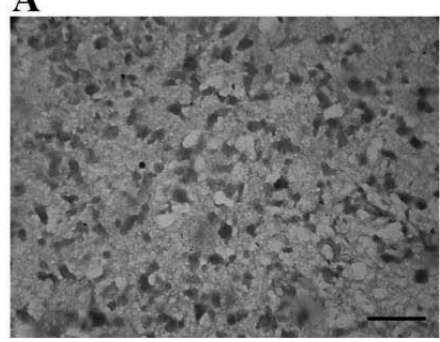

B

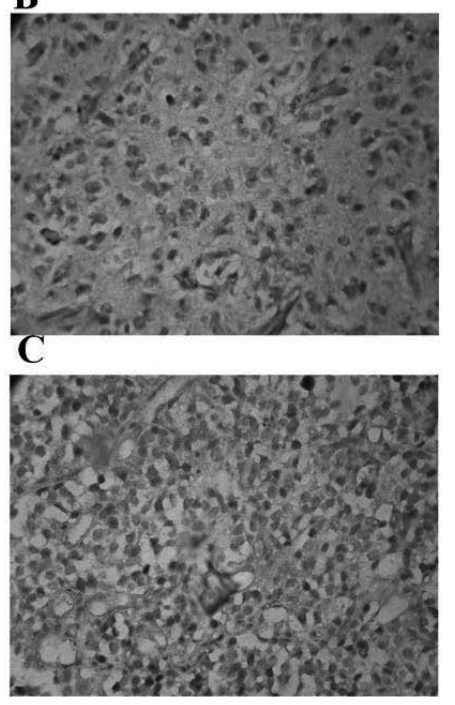

D

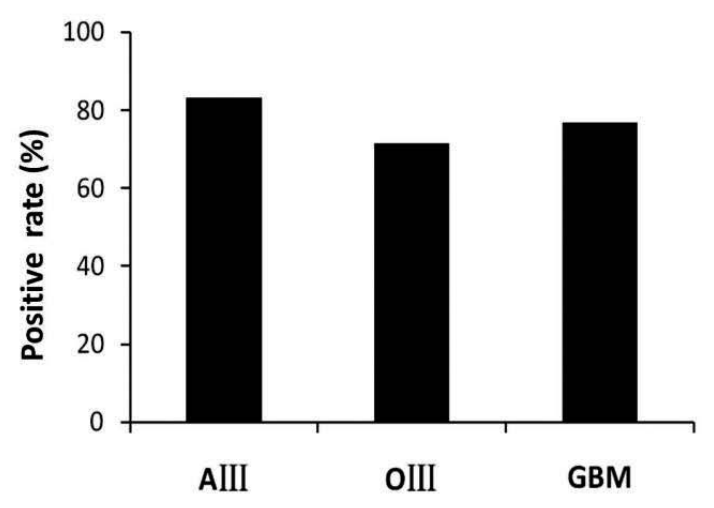

$\mathbf{E}$

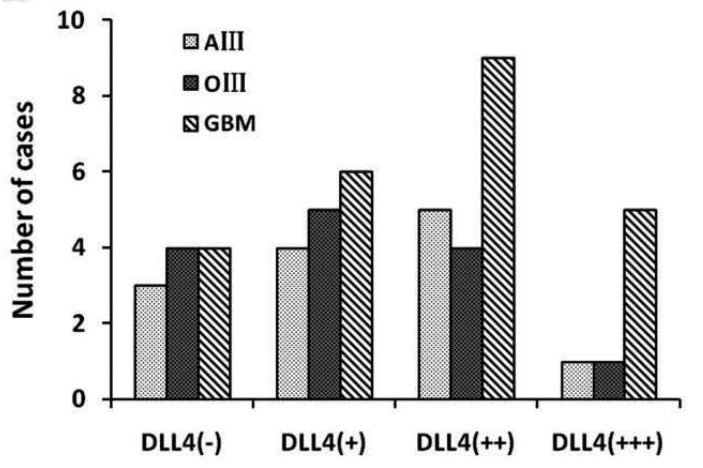

Fig. 1. Immunohistochemical staining of DLL4 in human high-grade malignant gliomas. The positive staining of DLL4 was observed in the cytoplasm of vascular endothelial cells and some tumor cells in AIII (A), OIII (B), and GBM (C). Among AIII $(\mathrm{n}=13)$, OIII $(\mathrm{n}=14)$ and GBM ( $\mathrm{n}=24)$, no significant difference in the positive rate of DLL4 (D) was observed $(p>0.05)$. However, the intensity of DLL4 protein staining (E) in GBM was significantly higher than in AIII and OIII $(\mathrm{p}<0.01)$. The scale bar represents $50 \mu \mathrm{m}$. 
we performed additional staining without the primary antibodies as negative control.

\section{Evaluation of DLL4 Staining}

Standard immunohistochemical staining was performed with a primary anti-DLL4 antibody (polyclonal, 1:250; Abcam, USA). The number of positive endothelial or tumor cells exhibiting positive DLL4 staining was counted using a light microscope at a magnification of $\times 200$. In each tumor specimen, 5 fields were examined. The expression was classified as negative (-) if $<10 \%$ of the cells were positive, and otherwise as positive. A semi-quantitative grading scale was adopted as follows: $(+)$ weak immunoreactivity (10-25\%), (++) moderate immunoreactivity (25-50\%), and $(+++)$ strong immunoreactivity $(\geq 50 \%)[14]$.

Figure 2

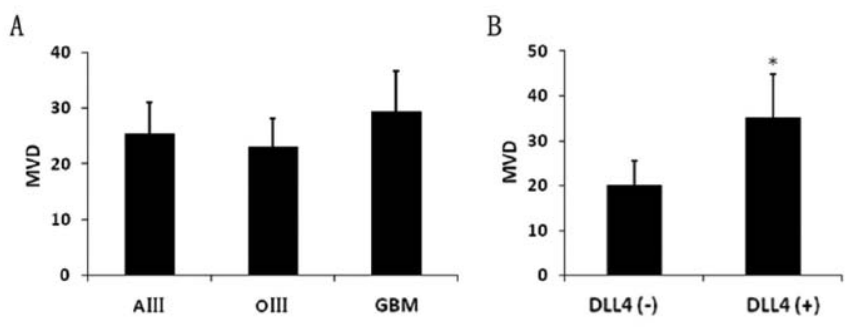

Fig. 2. MVD in high-grade malignant glioma and differential expression of DLL4. (A) Among AIII ( $\mathrm{n}=13)$, OIII $(\mathrm{n}=14)$, and GBM, the difference in MVD was not significant. (B) In DLL4-positive $(n=40)$ highgrade gliomas, MVD was higher than that in DLL4-negative $(\mathrm{n}=11)$ tissues $(\mathrm{p}<0.05)$.
Determination of Microvessel Density

The microvessel density (MVD) was counted using a light microscope at a magnification of $\times 400$, by counting CD31-labeled (anti-CD31 monoclonal antibody, 1:100; Dako, USA) microvessel endothelial cells in 'hot spots' displaying the most intense vascularization, which were identified at lower magnifications. Each positive endothelial cell or group of cells was counted as 1 individual vessel. The mean vessel count from 3 fields was used as the value for the MVD.

\section{Vessel Maturation Index}

$\alpha$-Smooth muscle actin ( $\alpha$-SMA) staining (monoclonal antibody, 1:500; Dako, USA) of pericytes, which were absent on immature blood vessels, was used to measure the degree of maturation. The total areas of CD31and/or $\alpha$-SMA-positive staining were obtained. The vessel maturation index (VMI) was then calculated as the percentage of mature vessels ( $\alpha$-SMA-positive) to CD31-positive vessels [4].

\section{Analysis of Protein Coexpression}

Double labeling immunofluorescence of frozen sections was used to detect the coexpression of 2 different proteins, such as EphrinB2 (monoclonal antibody, 1:100; Santa Cruz, USA) or EphB4 (monoclonal antibody, 1:50; Santa Cruz, USA) with CD31, EphrinB2 or EphB4 with DLL4, and $\alpha$-SMA with DLL4. For fluorescent visualization, secondary antibodies were labeled with CY3 or fluorescein isothiocyanate (FITC; Invitrogen, USA), while nuclei were detected with $0.5 \mu \mathrm{g} / \mathrm{ml}$ of Hoechst 33342. Fluorescent images of tumor sections were captured and analyzed with a Leica fluorescence microscope.

\section{Statistical Analysis}

Data are presented as mean \pm standard error (SE). All data were analyzed using SPSS 13.0 software. The chi-square $\left(\chi^{2}\right)$ test and Spearman's
Fig. 3. Vessel maturation in high-grade gliomas with differential DLL4 expression. Vessel pericytes were labeled by $\alpha$-SMA (A) and endothelial cells by CD31 (B). Among AIII $(\mathrm{n}=13)$, OIII $(\mathrm{n}=14)$, and GBM $(\mathrm{n}=24)$, no significant difference in VMI $(\mathbf{C})$ or the percentage of $\alpha$-SMA-positive vessels compared to CD31-positive vessels was observed. However, the VMI was significantly higher in DLL4-positive malignant gliomas compared with that in DLL4-negative tissues (D) $(\mathrm{p}<0.05)$. Coexpression of DLL4 (green) and $\alpha$-SMA (red) was observed in some vessels (E). The scale bar represents $50 \mu \mathrm{m}$.
A

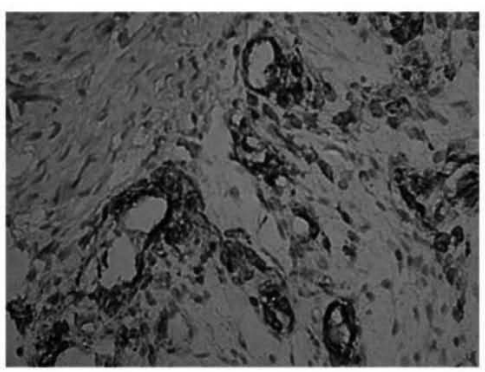

B

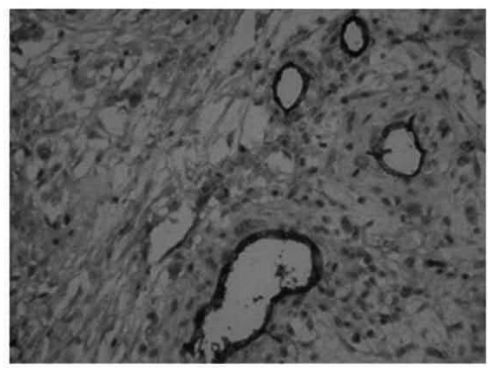

C

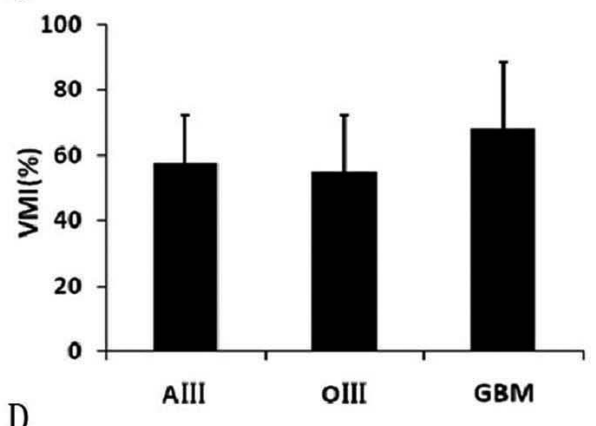

D

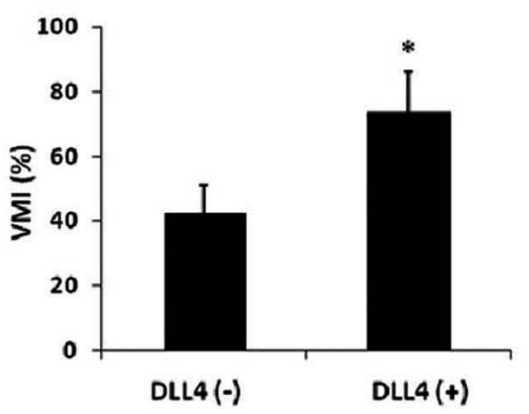

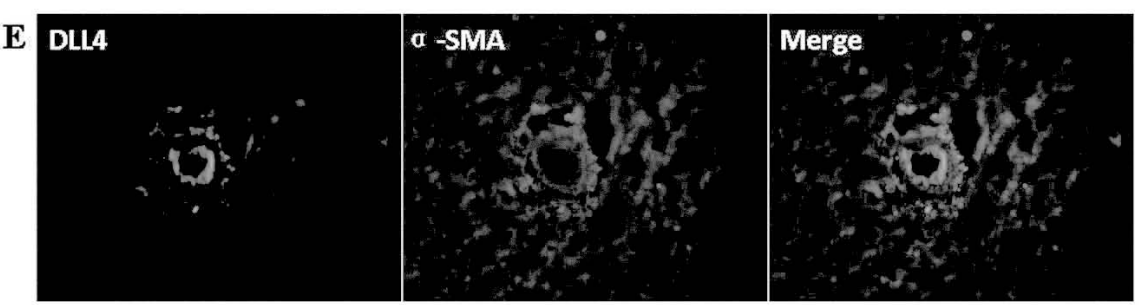


rank correlation $\left(\mathrm{r}_{\mathrm{s}}\right)$ analysis were performed; $\mathrm{p}<0.05$ was considered statistically significant.

\section{Results}

\section{Expression of DLL4 in High-Grade Malignant Glioma}

The positive staining of DLL4 was primarily distributed in the cytoplasm of tumor vascular endothelial cells in high-grade malignant glioma. Some tumor cells, especially those in perinecrotic areas, also showed positive cytoplasmic staining of DLL4. In $78.4 \%$ (40 out of 51) of all the malignant glioma specimens, DLL4 immunostaining was observed in tumor vascular endothelial cells, whereas in only $25.5 \%$ (13 out of 51 ) of the tumor cells staining was observed. DLL4 immunostaining was not observed in the parenchymal or vascular cells in any of the 7 normal brain tissues.

There was no significant difference in the DLL4-positive rate between AIII (76.9\%, 10 out of 13$)$, OIII (71.4\%, 10 out of 14$)$ and $\operatorname{GBM}(83.3 \%, 20$ out of 24) specimens. However, the DLL4-positive intensity in GBM was higher than those in AIII and OIII (fig. 1).

\section{Relationship of DLL4 with Vascular Endothelial Cell Proliferation}

Since immunoreactivity to CD31 was identified mainly in the vascular endothelial cells, vascular endothelial cell proliferation was analyzed by measuring the MVD with CD31 labeling. The MVD was not significantly different among AIII, OIII, and GBM. However, a relationship emerged between MVD and DLL4 expression. The MVD was markedly higher in tumors with DLL4 positive staining, as compared to those with negative staining (fig. 2).

\section{Relationship of DLL4 with Vessel Maturation in High-Grade Malignant Glioma}

As shown in figure $3 \mathrm{~A}$, vessel pericytes were immunoreactive to $\alpha$-SMA, which is regarded as the main feature of mature vessels. More notably, we observed that $\alpha$-SMA-positive cells were distributed in the zone of 2 neighboring vessels as a 'bridge'. Since CD31 stained both immature and mature vessels in glioma (fig. 3B), the percentage of $\alpha$-SMA-positive vessels to CD31-positive vessels was calculated, to evaluate the VMI of glioma. The mean VMI was $68.3 \pm 20.1 \%$ in GBM, $57.5 \pm 14.6 \%$ in AIII, and $54.8 \pm 17.4 \%$ in OIII. The VMI was significantly lower in tissues with DLL4 negative staining, as compared to those with DLL4 positive staining $(\mathrm{p}<0.01)$ (fig. 3C, D). Co-staining of DLL4 and $\alpha$-SMA was also shown in tumor vessels (fig. $3 \mathrm{E}$ ). These results indicated that vessel maturation in the tumor vasculature was significantly up-regulated in DLL4-positive tissues.

\section{Relationship of DLL4 with EphrinB2 and \\ EphB4 Expression in Vessels}

EphrinB2 and EphB4 staining was predominantly observed in the cytoplasm of tumor cells. A variable positive staining was also observed in some endothelial cells of tumor blood vessels. Neither EphrinB2 nor EphB4 positive expression observed in tumor cells or endothelial cells was significantly different among GBM, AIII and OIII. Since EphrinB2 and EphB4 are respectively regarded as markers for primitive arteries and veins and since DLL4 is required for normal

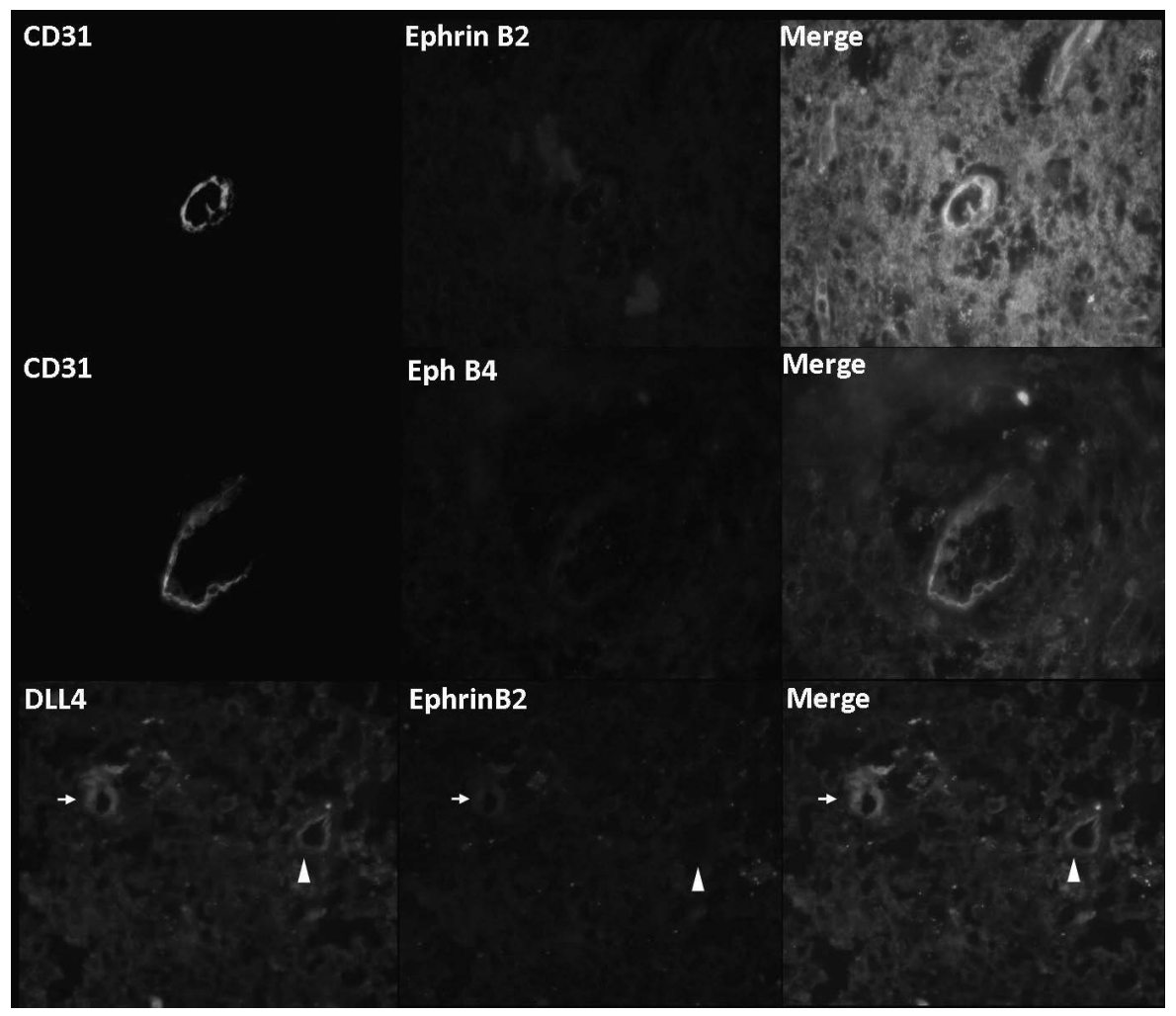

766
Fig. 4. Immunohistochemical staining of EphrinB2 and EphB4 in glioma vessels. Serial sections were stained for CD31 (green) and EphrinB2 or EphB4 (red) using immunofluorescence double staining. EphrinB2 (A) positive staining was predominantly observed in vessels with a small lumen and thick walls, whereas EphB4 (B) positive staining was primarily observed in vessels with a large lumen and thin walls. Co-staining of DLL4 (green) with EphrinB2 (red) was observed in tumor vascular endothelial cells (arrow) (C). The scale bar represents $50 \mu \mathrm{m}$. 
vascular development and arterial formation, we investigated the relationship of DLL4 with EphrinB2 and EphB4 expression in glioma vessels. Interestingly, in tumor vessels with positive staining, EphrinB2 positive staining was mainly observed in vessels with a small lumen and thick walls (fig. 4A), whereas EphB4 positive staining was observed in vessels with a large lumen and thin walls (fig. 4B). There was little costaining of DLL4 with EphrinB2 in tumor endothelial cells (fig. 4C), whereas co-staining of DLL4 with EphB4 in tumor endothelial cells was not observed. These results indicated that a relationship between DLL4 and EphrinB2 or EphB4 was not present in tumor vessels.

\section{Discussion}

Angiogenesis is an essential component of the carcinogenesis mechanism of malignant glioma. Once a tumor reaches a certain size, new blood vessels are required to continue growth. Multiple pro-angiogenic growth factors, which are mainly secreted by tumor cells, play pivotal roles in the proliferation, migration and differentiation of endothelial cells. During the process of angiogenesis, a closely coordinated balance between endothelial cell sprouting and the maintenance of existing vascular tubes is required. This equilibrium can be mediated by DLL4 in endothelial tip cells that activate Notch signaling, and thereby suppress the sprouting of adjacent endothelial cells [5]. The expression of DLL4 appears to be regulated directly by VEGF and a hypoxic microenviroment in the setting of tumor angiogenesis [15]. In our previous study, we observed a positive relationship between DLL4, VEGF and hypoxia-inducible factor $1 \alpha(\mathrm{HIF}-1 \alpha)$ in glioma tissues [16]. Increased levels of VEGF led to an up-regulation of DLL4 expression $[15,17]$, which signaled to endothelial cells expressing Notch receptors to down-regulate VEGF-induced sprouting and branching [5]. In this pathway, DLL4 acts as a negative modulator of angiogenesis, regulating excessive VEGF-induced vessel branching and allowing vessel formation to occur at a productive and efficient rate [5]. Therefore, maintaining the balance of DLL4 and VEGF in malignant glioma is pivotal to promote the functional angiogenesis of tumors.

To the best of our knowledge, the present study is the first to systemically investigate the relationship of DLL4 with the vascular quantity and quality in malignant glioma. We first observed the pattern and level of DLL4 protein expression in human glioma tissues using immunohistochemistry techniques. Herein, we showed that DLL4 expression was significantly up-regulated in human malignant gliomas compared with that in normal brain tissues. The immunoreactivity of DLL4 was stronger in GBM than in AIII and OIII. The current findings are consistent with previous studies showing that DLL4 was highly expressed in human colon cancers, superficial and invasive bladder cancers, clear-cell renal cell carcinomas, breast cancers, and pancreatic cancers [15, 18-21].
DLL4 is involved in embryonic vascular development and tumor angiogenesis. Therefore, we explored the relationship of DLL4 with microvessel number and maturation in glioma tissues. Vessel maturation has been previously evaluated in different types of human glioma tissues by analyzing $\alpha$-SMA staining in tumor vessels [4, 22, 23]. Gesundheit et al. [4] demonstrated that the VMI, measured by the $\alpha$-SMA/CD31 ratio, was different between pilocytic and anaplastic astrocytoma in children. Takeuchi et al. [22] showed that the VMI of the boundary was significantly lower than that of the tumor and perinecrosis in GBM, and that the VMI of the highVEGF group was significantly higher than that of the lowVEGF group in GBM. Here, we showed a clear difference between DLL4-positive and -negative malignant glioma tissues in the proliferation of vascular endothelial cells and recruitment of pericytes, which are considered a hallmark of vessel stabilization and maturation. A significant positive correlation was found between DLL4 and the MVD or VMI. Our results are in accordance with the study by Patel et al. [19], which showed that $98.7 \%$ of DLL4-positive tumor vessels coexpressed $\alpha$-SMA, whereas only $64.5 \%$ of DLL4negative tumor vessels coexpressed $\alpha$-SMA. Gesundheit et al. [4] also demonstrated that the VMI was different between small and large vessels in anaplastic astrocytoma. An extremely low VMI was observed for small vessels in astrocytoma $(6.1 \%)$, whereas the VMI for large vessels was $56 \%$. The marked predominance of small immature vessels in astrocytoma may indicate active, ongoing angiogenesis. Since mature, well-differentiated vasculature results in a high VMI and functional irrigation, the noteworthy difference in vascular maturation may represent a fast-growing tumor in DLL4positive tissues. On the other hand, impaired DLL4/Notch expression or function may lead to excessive but nonproductive sprouting [24]. Recent studies have reported that DLL4 blockade resulted in nonproductive angiogenesis due to the development of thin, dense and non-perfusing vessels with few pericytes [9].

Eph receptor tyrosine kinases and their membrane-bound Ephrin ligands mediate various cell-to-cell communications by bidirectional signaling and are involved in numerous developmental processes [25]. In vascular development, Eph class $\mathrm{B}$ receptors $(\mathrm{EphB})$ and their ligands have attracted the most attention because their homozygous mutation results in embryonic lethality, and EphrinB2 is involved in the maturation of tumor blood vessels [26]. EphrinB2 is considered a marker for primitive arteries and EphB4 is regarded as a marker for primitive veins [27]. DLL4 is also a key factor in determining the arterial or venous fate of endothelial cells. In co-culture experiments using endothelial cells and DLL4-expressing cells, Iso et al. [28] found that DLL4 stimulation markedly induced EphrinB2 expression, suggesting that DLL4-stimulated Notch signaling induces certain arterial characteristics in endothelial cells. Based on these findings, we investigated the relationship between DLL4 and EphrinB2 and EphB4 in glioma vessels. We found that EphrinB2 and EphB4 were 
mainly expressed in tumor cells and some tumor vessels. Interestingly, EphrinB2 was mainly observed in small, thickwalled vessels whereas EphB4 was seen in large, thin-walled vessels. It is traditionally believed that vessels in tumors originate from the veins. Here, thick-walled vessels stained with EphrinB2 implicated that vessels could also originate from the primitive arteries in malignant glioma. However, no correlation between DLL4 and EphrinB2 or EphB4 in tumor endothelial cells was observed. This may be due to the complicated mechanism of endothelial cell differentiation, which is regulated by oxygen status [29], shear stress [30], VEGF [30], and other unknown factors.

Since many of the currently available angiogenesis inhibitors inhibit immature vessels, the VMI in glioma may be a useful biomarker for predicting the efficiency of antiangiogenic treatments. Alternatively, anti-angiogenic agents may normalize the vascular pattern and improve the transport of drugs and oxygen, leading to more effective radiotherapy in well-oxygenated tumors. Therefore, it is promising to improve the effect of anti-angiogenic agents by first inhibiting DLL4, which may alter the glioma vessel maturity.

\section{Acknowledgements}

The work was supported by a grant for young talents from the Hubei Provincial Health Department (QJX2008-32). We thank Medjaden Bioscience Limited for assisting in the preparation of this manuscript.

\section{Disclosure Statement}

The authors declare no conflict of interest.

\section{References}

1 Yamanaka R, Saya H: Molecularly targeted therapies for glioma. Ann Neurol 2009;66:717-729.

- 2 Jain RK, di Tomaso E, Duda DG, Loeffler JS, Sorensen AG, Batchelor TT: Angiogenesis in brain tumours. Nat Rev Neurosci 2007;8:610-622.

$\checkmark 3$ Jensen RL: Brain tumor hypoxia: Tumorigenesis, angiogenesis, imaging, pseudoprogression, and as a therapeutic target. J Neurooncol 2009;92:317335 .

4 Gesundheit B, Klement G, Senger C, Kerbel R, Kieran M, Baruchel S, Becker L: Differences in vasculature between pilocytic and anaplastic astrocytomas of childhood. Med Pediatr Oncol 2003; 41:516-526.

5 Hellstrom M, Phng LK, Hofmann JJ, Wallgard E, Coultas L, Lindblom P, Alva J, Nilsson AK, Karlsson L, Gaiano N, Yoon K, Rossant J, Iruela-Arispe ML, Kalen M, Gerhardt $\mathrm{H}$, Betsholtz C: DLL4 signalling through Notch1 regulates formation of tip cells during angiogenesis. Nature 2007:445:776-780.

6 Li ZQ, Yuan XH, Wu T, Wu ZM, Wen ZH: Expression of VEGF, MMPs and its relation with vascular ultrastructure in primary and recurrent gliomas. Chin J Neuromed 2005;4:994-997.

7 Li JL, Sainson RC, Shi W, Leek R, Harrington LS, Preusser M, Biswas S, Turley H, Heikamp E, Hainfellner JA, Harris AL: Delta-like 4 Notch ligand regulates tumor angiogenesis, improves tumor vascular function, and promotes tumor growth in vivo. Cancer Res 2007;67:11244-11253.

$\checkmark$ Noguera-Troise I, Daly C, Papadopoulos NJ, Coetzee S, Boland P, Gale NW, Lin HC, Yancopoulos GD, Thurston G: Blockade of DLL4 inhibits tumour growth by promoting non-productive angiogenesis. Nature 2006;444:1032-1037.

-9 Scehnet JS, Jiang W, Kumar SR, Krasnoperov V, Trindade A, Benedito R, Djokovic D, Borges C, Ley EJ, Duarte A, Gill PS: Inhibition of DLL4mediated signaling induces proliferation of immature vessels and results in poor tissue perfusion. Blood 2007;109:4753-4760.

10 Ridgway J, Zhang G, Wu Y, Stawicki S, Liang WC, Chanthery Y, Kowalski J, Watts RJ, Callahan C, Kasman I, Singh M, Chien M, Tan C, Hongo JA, de Sauvage F, Plowman G, Yan M: Inhibition of DLL4 signalling inhibits tumour growth by deregulating angiogenesis. Nature 2006;444:1083-1087.
11 Louis DN, Ohgaki H, Wiestler OD, Cavenee WK, Burger PC, Jouvet A, Scheithauer BW, Kleihues P The 2007 WHO classification of tumours of the central nervous system. Acta Neuropathol 2007; 114:97-109.

12 Gesuete R, Storini C, Fantin A, Stravalaci M, Zanier ER, Orsini F, Vietsch H, Mannesse ML, Ziere B, Gobbi M, De Simoni MG: Recombinant $\mathrm{C} 1$ inhibitor in brain ischemic injury. Ann Neurol 2009;66:332-342.

13 Kang YJ, Digicaylioglu M, Russo R, Kaul M, Achim CL, Fletcher L, Masliah E, Lipton SA: Erythropoietin plus insulin-like growth factor-I protects against neuronal damage in a murine model of human immunodeficiency virus-associated neurocognitive disorders. Ann Neurol 2010; 68:342-352.

14 Kosarac O, Takei H, Zhai OJ, Schwartz MR, Mody DR: S100P and XIAP expression in pancreatic ductal adenocarcinoma: Potential novel biomarkers as a diagnostic adjunct to fine needle aspiration cytology. Acta Cytol 2011;55:142-148.

15 Patel NS, Li JL, Generali D, Poulsom R, Cranston DW, Harris AL: Up-regulation of deltalike 4 ligand in human tumor vasculature and the role of basal expression in endothelial cell function. Cancer Res 2005;65:8690-8697.

16 Li Z, Wang J, Gong L, Wen Z, Xu C, Huang X: Correlation of delta-like ligand 4 (DLL4) with VEGF and HIF-1alpha expression in human glioma. Asian Pac J Cancer Prev 2011;12:215-218.

17 Hainaud P, Contreres JO, Villemain A, Liu LX, Plouet J, Tobelem G, Dupuy E: The role of the vascular endothelial growth factor-delta-like 4 ligand/Notch4-Ephrin B2 cascade in tumor vessel remodeling and endothelial cell functions. Cancer Res 2006;66:8501-8510.

18 Jubb AM, Turley H, Moeller HC, Steers G, Han C, Li JL, Leek R, Tan EY, Singh B, Mortensen NJ, Noguera-Troise I, Pezzella F, Gatter KC, Thurston G, Fox SB, Harris AL: Expression of delta-like ligand 4 (DLL4) and markers of hypoxia in colon cancer. Br J Cancer 2009;101:1749-1757.

19 Patel NS, Dobbie MS, Rochester M, Steers G, Poulsom R, Le Monnier K, Cranston DW, Li JL, Harris AL: Up-regulation of endothelial delta-like 4 expression correlates with vessel maturation in bladder cancer. Clin Cancer Res 2006;12:4836-4844.
20 Shi W, Harris AL: Notch signaling in breast cancer and tumor angiogenesis: Cross-talk and therapeutic potentials. J Mammary Gland Biol Neoplasia 2006; 11:41-52.

21 Buchler P, Gazdhar A, Schubert M, Giese N, Reber HA, Hines OJ, Giese T, Ceyhan GO, Muller M, Buchler MW, Friess H: The Notch signaling pathway is related to neurovascular progression of pancreatic cancer. Ann Surg 2005;242:791-800, discussion 800-791.

22 Takeuchi H, Hashimoto N, Kitai R, Kubota T, Kikuta K: Proliferation of vascular smooth muscle cells in glioblastoma multiforme. J Neurosurg 2010; 113:218-224.

23 Eberhard A, Kahlert S, Goede V, Hemmerlein B, Plate KH, Augustin HG: Heterogeneity of angiogenesis and blood vessel maturation in human tumors: Implications for antiangiogenic tumor therapies. Cancer Res 2000;60:1388-1393.

24 Benedito R, Roca C, Sorensen I, Adams S, Gossler A, Fruttiger M, Adams RH: The Notch ligands DLL4 and Jagged1 have opposing effects on angiogenesis. Cell 2009;137:1124-1135.

25 Pasquale EB: Eph receptor signalling casts a wide net on cell behaviour. Nat Rev Mol Cell Biol 2005:6:462-475.

-26 Yamanda S, Ebihara S, Asada M, Okazaki T, Niu K, Ebihara T, Koyanagi A, Yamaguchi N, Yagita H, Arai H: Role of EphrinB2 in nonproductive angiogenesis induced by delta-like 4 blockade. Blood 2009;113:3631-3639.

27 Kume T: Specification of arterial, venous, and lymphatic endothelial cells during embryonic development. Histol Histopathol 2010;25:637-646.

28 Iso T, Maeno T, Oike Y, Yamazaki M, Doi H, Arai M, Kurabayashi M: DLL4-selective Notch signaling induces EphrinB2 gene expression in endothelial cells. Biochem Biophys Res Commun 2006;341:708-714.

29 Claxton S, Fruttiger M: Oxygen modifies artery differentiation and network morphogenesis in the retinal vasculature. Dev Dyn 2005;233:822828.

30 Masumura T, Yamamoto K, Shimizu N, Obi S, Ando J: Shear stress increases expression of the arterial endothelial marker EphrinB2 in murine ES cells via the VEGF-Notch signaling pathways. Arterioscler Thromb Vasc Biol 2009;29:2125-2131. 